\title{
Multiferroism and enhancement of material properties across the morphotropic phase boundary of $\mathrm{BiFeO}_{3}-\mathrm{PbTiO}_{3}$
}

\author{
H. Amorín, ${ }^{1}$ C. Correas, ${ }^{1}$ C. M. Fernández-Posada, ${ }^{1}$ O. Peña,${ }^{2}$ A. Castro, ${ }^{1}$ \\ and M. Alguerón ${ }^{1, a)}$ \\ ${ }^{1}$ Instituto de Ciencia de Materiales de Madrid (ICMM), CSIC. Cantoblanco, Madrid 28049, Spain \\ ${ }^{2}$ Sciences Chimiques de Rennes, UMR 6226, Université de Rennes 1. Rennes 35042, France
}

(Received 22 January 2014; accepted 1 March 2014; published online 12 March 2014)

\begin{abstract}
Strong phase-change magnetoelectric responses have been anticipated by a first-principles investigation of phases in the perovskite $\mathrm{BiFeO}_{3}-\mathrm{BiCoO}_{3}$ solid solution, specifically at the morphotropic phase boundary (MPB) between the multiferroic rhombohedral and tetragonal polymorphs. This might be a general property of multiferroic MPBs and a novel promising approach for room temperature magnetoelectricity, which requires the identification of suitable material systems. We present here a comprehensive description of the electrical and electromechanical properties across one such system; the perovskite $\mathrm{BiFeO}_{3}-\mathrm{PbTiO}_{3}$ solid solution. All the temperature dependence of dielectric permittivity, ferroelectric hysteresis loops, and piezoelectric coefficients have been obtained, and are discussed in relation to the previously reported perovskite structural evolution. Results show ceramic materials to be very promising for ferroelectric random access memories (remnant polarization as high as $63 \mu \mathrm{Ccm}^{-2}$ with a comparatively low coercive field of $4.5 \mathrm{kV} \mathrm{mm}^{-1}$ for MPB compositions) and high temperature electromechanical transduction (crystal piezoelectric coefficient of $87 \mathrm{pC} \mathrm{N}^{-1}$ with a Curie temperature above $873 \mathrm{~K}$ ). Moreover, the occurrence of phase changes between the monoclinic and tetragonal polymorphs under high electric fields is indicated, while the canted antiferromagnetic character of the phases involved is corroborated. (C) 2014 AIP Publishing LLC. [http://dx.doi.org/10.1063/1.4868319]
\end{abstract}

\section{INTRODUCTION}

The perovskite $\mathrm{BiFeO}_{3}-\mathrm{PbTiO}_{3}$ solid solution currently attracts a great deal of attention in terms of both applications and fundamental issues. $\mathrm{BiFeO}_{3}$ is the most topical multiferroic material, ${ }^{1}$ for it is perhaps the only compound that shows magnetic ordering and proper ferroelectricity at room temperature. ${ }^{2}$ This compound is a ferroelectric perovskite oxide with a transition temperature of $\sim 1100 \mathrm{~K}, 2,3$ a rhombohedral structure with space group $R 3 c,{ }^{4}$ and a room temperature (RT) spontaneous polarization exceeding $100 \mu \mathrm{C} \mathrm{cm}^{-2}$. This latter figure makes the compound extremely interesting for high density ferroelectric random access memories. ${ }^{6,7}$ However, conductivity is an issue, and coercive field is very high. Applicability thus, requires a stringent control of the defect chemistry, usually addressed by chemical modification that can be tailored to also decrease the coercive field. Besides, the oxide is a G-type antiferromagnet with an ordering temperature of $643 \mathrm{~K}^{8}{ }^{8}$ Crystal magnetoelectric coupling exists, and results in spin canting but also in a long range incommensurate cycloid superstructure. ${ }^{9,10}$ Weak ferromagnetism is only obtained when the latter spin cycloid is destroyed by epitaxial strain $\left(M_{s} \approx 0.6 \mathrm{emu} \mathrm{\textrm {g } ^ { - 1 }}\right.$ for $200 \mathrm{~nm}$ thick, $\langle 111\rangle$-oriented films), ${ }^{11}$ as a size effect $\left(M_{s} \sim 1 \mathrm{emu} \mathrm{g}^{-1} \text { for } 14 \mathrm{~nm} \text { diameter particles }\right)^{12}$ or by doping ( $M_{s}=1.2 \mathrm{emu} \mathrm{g}^{-1}$ for $\mathrm{Bi}_{0.7} \mathrm{Ba}_{0.3} \mathrm{FeO}_{3}$ ceramic materials). ${ }^{13}$

\footnotetext{
a) Author to whom correspondence should be addressed. Electronic mail: malguero@icmm.csic.es
}

The perovskite structural evolution across the $\mathrm{x}$ $\mathrm{BiFeO}_{3}-(1-\mathrm{x}) \mathrm{PbTiO}_{3}$ solid solution has been extensively studied over the last years. Coexistence of rhombohedral $R 3 c$ and tetragonal $P 4 \mathrm{~mm}$ polymorphs has been reported across a composition range that can be as wide as $0.8 \geq \mathrm{x} \geq 0.6,{ }^{14,15}$ but that narrows down to $0.73>x>0.69$ for chemically homogeneous and stoichiometric ceramic samples. ${ }^{16}$ These coexisting polymorphic phases would be then isostructural with the edge ferroelectric oxides of the binary system, and a ferroelectric morphotropic phase boundary (MPB), similarly to those described for $\mathrm{Pb}(\mathrm{Zr}, \mathrm{Ti}) \mathrm{O}_{3}, \mathrm{~Pb}\left(\mathrm{Mg}_{1 / 3} \mathrm{Nb}_{2 / 3}\right) \mathrm{O}_{3^{-}} \mathrm{PbTiO}_{3}$, or $\mathrm{Pb}\left(\mathrm{Zn}_{1 / 3} \mathrm{Nb}_{2 / 3}\right) \mathrm{O}_{3}-\mathrm{PbTiO}_{3}$ might exist in the solid solution. Very high piezoelectric response has been found at these MPBs, and associated with the existence of intermediate, bridging polymorphs. ${ }^{17}$ Evidences of an intermediate MPB phase for $\mathrm{BiFeO}_{3}-\mathrm{PbTiO}_{3}$ were first provided by electron diffraction, ${ }^{18}$ and latest Rietveld refinements of X-ray diffraction data have shown it to be monoclinic $C c$, and to extend up $\mathrm{x}=0.9 .^{19}$

A number of reports have addressed the magnetic properties. The antiferromagnetic ordering temperature of the rhombohedral (actually monoclinic for $\mathrm{x}<0.9$ ) phase was followed by superconducting quantum interference device (SQUID) magnetometry, and found to decrease from $630 \mathrm{~K}$ for $\mathrm{x}=1$ down to $\sim 520 \mathrm{~K}$ for $\mathrm{x}=0.72 .{ }^{15} \mathrm{G}$-type antiferromagnetism and a Neel temperature of $592 \mathrm{~K}$ were obtained in an independent neutron diffraction study of $\mathrm{x}=0.9 .{ }^{20}$ At the MPB region, the coexisting monoclinic and tetragonal polymorphs have well differentiated antiferromagnetic order and Neel temperature, ${ }^{21}$ the latter being below room temperature 
TABLE I. Processing conditions, either hot pressing (HP) or SPS at pressure $\mathrm{P}_{\text {Sint }}$ and temperature $\mathrm{T}_{\text {Sint }}$ for the different $\mathrm{x} \mathrm{BiFeO}_{3}-(1-\mathrm{x}) \mathrm{PbTiO}_{3}$ ceramic materials. A postsintering treatment in air at temperature $\mathrm{T}_{\text {Post-an }}$ was carried out for SPS materials. Remnant polarization $P_{R}$, coercive field $E_{C}$, Curie temperature on heating $T_{C}{ }^{h}$, and room temperature $\varepsilon_{33}$ dielectric permittivity and $d_{33}$ piezoelectric coefficient for the materials. *Saturation not attained.

\begin{tabular}{lccccccccc}
\hline \hline$x$ & Sint. & $P_{\text {Sint }}(\mathrm{MPa})$ & $T_{\text {Sint }}(\mathrm{K})$ & $T_{\text {Post -an }}(\mathrm{K})$ & $P_{R}\left(\mu \mathrm{C} \mathrm{cm}^{-2}\right)$ & $E_{C}\left(\mathrm{kV} \mathrm{mm}^{-1}\right)$ & $T_{C}{ }^{h}(\mathrm{~K})$ & $\varepsilon_{33}\left(x \varepsilon_{o}\right)$ & $d_{33}(\mathrm{pC} \mathrm{N})$ \\
\hline 1 & $\mathrm{HP}$ & 60 & 1053 & $\ldots$ & $12^{*}$ & $7.2^{*}$ & 1105 & 48 \\
0.9 & $\mathrm{HP}$ & 60 & 1123 & $\ldots$ & 46 & 12 & 1048 & 95 \\
0.8 & $\mathrm{HP}$ & 60 & 1123 & $\ldots$ & 45 & 8 & 969 & 139 \\
0.7 & $\mathrm{HP}$ & 60 & 1223 & $\ldots$ & 36 & 5 & 894 & 265 \\
0.675 & $\mathrm{HP}$ & 60 & 1223 & $\ldots$ & 63 & $\ldots$ & 914 & 335 \\
0.6 & $\mathrm{SPS}$ & 1000 & 673 & 1073 & $\ldots$ & 877 & 50 & 87 \\
\hline \hline
\end{tabular}

for the tetragonal phase. ${ }^{22}$ Monoclinic materials also present a second magnetic anomaly in their susceptibility below the ordering temperature, ${ }^{15}$ which has been associated with a spin reorientation transition. ${ }^{23}$ This scenario opens the door to significant magnetoelectric effects associated with electric field induced phase transitions between the perovskite polymorphs, as those anticipated for $\mathrm{BiFeO}_{3}-\mathrm{BiCoO}_{3}{ }^{24}$ Indeed, a very high phase-change electromechanical response was recently reported for $\mathrm{MPB} \mathrm{BiFeO}_{3}-\mathrm{PbTiO}_{3} .{ }^{25}$

Unfortunately, reports on the electrical properties across the solid solution are scarce, most probably because conductivity often prevented reliable data to be obtained. ${ }^{26} \mathrm{~A}$ previous study was only focused on $\mathrm{x}=0.7$, and reported the temperature dependence of permittivity at $100 \mathrm{kHz}$ and $1 \mathrm{MHz} .{ }^{27}$ A Curie temperature of $923 \mathrm{~K}$ was established, yet thermal hysteresis was not addressed. A maximum relative permittivity in excess of 10000 was found at the transition. Besides, pinched ferroelectric loops were obtained. Columnar films on Pt/Si substrates with $\mathrm{x}=0.4$ have also been prepared by pulsed laser deposition, and showed a remnant polarization of $\approx 50 \mu \mathrm{C} \mathrm{cm}^{-2}$ and a coercive field of $23 \mathrm{kV} \mathrm{mm}^{-1}$. $^{28}$

We report here an in-depth study of the electrical and electromechanical properties along the perovskite $\mathrm{BiFeO}_{3}$ $\mathrm{PbTiO}_{3}$ solid solution, across its multiferroic phase boundary and entering the tetragonal field of the phase diagram. Emphasis is put on describing the evolution of properties in relation to the previously reported structural one, and on discussing the relevance of the possible underneath mechanisms like domain wall movements, lattice transverse softening, and phase-change phenomena.

\section{EXPERIMENTAL}

The description of the electrical properties across the $\mathrm{x}$ $\mathrm{BiFeO}_{3}-(1-\mathrm{x}) \mathrm{PbTiO}_{3}$ system was only possible after the processing of high-quality ceramic materials for all compositions. This was especially challenging in the case of perovskite tetragonal single phases close to the MPB region, such as $\mathrm{x}=0.6$ that presented a tetragonal distortion as high as $\sim 1.165 .^{16,29}$

Perovskite phase nanocrystalline powders were obtained by mechanosynthesis in a high energy planetary mill. This is a powerful means of preparing nanoscale perovskite oxides, which allows most of the multiferroic compounds under focus, even high pressure phases, to be obtained. ${ }^{30,31}$ In the case of $\mathrm{BiFeO}_{3}-\mathrm{PbTiO}_{3}$, single phase powders were synthesized all across the system as explained elsewhere. ${ }^{29}$ Dense ceramics were processed by hot pressing of the nanocrystalline powder down to $x=0.675$. A stringent control of the preparation conditions was required to obtain high-quality ceramic materials, suitable for electrical characterization. The electrical properties here reported correspond to materials that showed tailored conduction related phenomena (and also enhanced dielectric breakdown resistance), which happened to be those with grain size between 0.5 and $1 \mu \mathrm{m}$. A summary of the preparation conditions is provided in Table I.

In the case of $\mathrm{x}=0.6$, materials could not be processed by hot pressing, for ceramic disintegration took place during cooling, most probably associated with the ferroelectric transition and the development of the very large tetragonal strain. Dense ceramics of this specific composition were thus processed by spark plasma sintering (SPS) of the nanocrystalline powder, followed by a second thermal treatment in air to trigger grain growth up to the submicron range. A microstructure comparable to those of hot pressed materials was achieved. Specific conditions are also given in the table.

Materials presented the anticipated perovskite structural evolution with decreasing $\mathrm{x}$, as monitored with $\mathrm{X}$-ray diffraction (XRD). Measurements were carried out with a Siemens D500 powder diffractometer with $\mathrm{CuK}_{\alpha}$ radiation between $15^{\circ}$ and $55^{\circ}(2 \theta)$ with a $0.05^{\circ}(2 \theta)$ step and $5 \mathrm{~s}$ counting time. Patterns for selected powdered samples across the MPB are shown in Fig. 1. Note the evolution from the

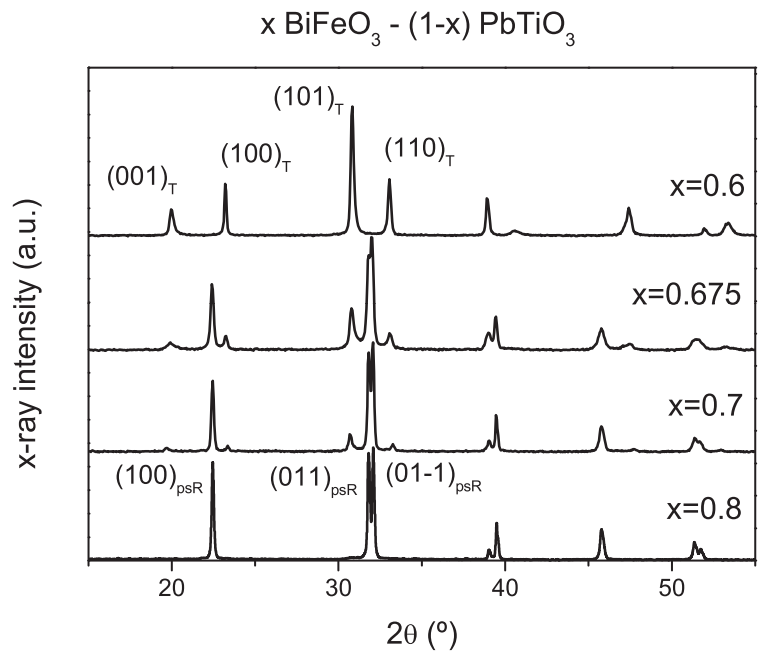

FIG. 1. XRD patterns for $x \mathrm{BiFeO}_{3}-(1-\mathrm{x}) \mathrm{PbTiO}_{3}$ samples across the MPB. Selected peaks of the tetragonal (T) and pseudo-rhombohedral (psR) polymorphic phases are labeled with their Miller indexes. 
pseudo-rhombohedral (monoclinic according to literature) phase to the tetragonal one through a region of coexistence.

Electrical properties were characterized on thinned; down to $0.5 \mathrm{~mm}$ thickness ceramic discs, on which Au electrodes were painted and sintered at $1073 \mathrm{~K}$. Real and imaginary components of the permittivity were obtained from capacitance and loss tangent measurements, carried out with a HP4284A precision LCR meter. This was done in two temperature ranges; from $\mathrm{RT}$ to $1073 \mathrm{~K}(1123 \mathrm{~K}$ in the only case of $\mathrm{BiFeO}_{3}$ ), and from 77 to $773 \mathrm{~K}$ during heating/cooling cycles with $\pm 1.5^{\circ} \mathrm{C} \mathrm{min}{ }^{-1}$ rate, at several frequencies between $100 \mathrm{~Hz}$ and $1 \mathrm{MHz}$. A Cryostat Janis VPF 700 coupled to a temperature controller Lakeshore 331 and vacuum conditions were used in the latter case.

Room temperature, high electric field electrical properties were also studied. Low frequency $(0.01,0.1$, and $1 \mathrm{~Hz})$ voltage sine waves were applied with amplitudes up to $10 \mathrm{kV}$ by the combination of a synthesizer/function generator (HP 3325B) and a high voltage amplifier (TREK model $10 / 40$ ), and charge was measured with a homebuilt charge to voltage converter and software for loop acquisition and analysis. Results are presented at $0.1 \mathrm{~Hz}$ (a trade-off between approaching saturation and minimizing non-ferroelectric contributions) both before and after compensation for subtracting the linear polarization and conduction contributions, evaluated from the current response at very low fields, assuming a resistance and a capacitance in parallel.

Poling could only be accomplished at room temperature and under high-field and very-low frequency $(0.01 \mathrm{~Hz})$ sine waves, for static fields applied during prolonged times resulted in the electrical breakdown of samples. This was done by increasing the amplitude in steps up to the maximum field attained during loop measurements, maintaining the sample for 5 cycles at maximum field, and removing the field just before completing the fifth one. Samples were then allowed to relax for $1 \mathrm{~h}$, after which the linear $d_{33}$ piezoelectric charge was measured with a Berlincourt-type piezometer.

Finally, the magnetic properties of selected compositions at the MPB region were characterized with a Quantum Design MPMS-XL5 SQUID magnetometer. Magnetization was measured between 2 and $400 \mathrm{~K}$ after zero field cooling (ZFC) and during subsequent field cooling (FC) under an applied field of $500 \mathrm{Oe}$, and as a function of magnetic field at room temperature.

\section{RESULTS}

Results are presented and preliminarily discussed in three sections. $\mathrm{BiFeO}_{3}$ is separately treated because measurements posed distinctive challenges, associated with the high transition temperature next to the perovskite decomposition one. $\mathrm{BiFeO}_{3}-\mathrm{PbTiO}_{3}$ ceramic materials processed by hot pressing are addressed in a second section. These are materials either rhombohedral/monoclinic single phase, or at the morphotropic phase boundary, but that could withstand the ceramic stresses developed during thermal cycling across the ferroelectric transition. Finally, results for ceramics of compositions at the tetragonal side of the MPB, which showed very large perovskite distortion, and could only be processed by spark plasma sintering are given. Unlike the previous materials, mechanical strength was an issue during the high-field electrical measurements due to microcracking and dielectric breakdown.

\section{A. $\mathrm{BiFeO}_{3}$ ceramics}

The temperature dependence of the real permittivity, measured during heating from $77 \mathrm{~K}$ up to $773 \mathrm{~K}$ is shown in Fig. 2(a). Note the presence of a step-like increase of permittivity at temperatures above RT, whose height and position decreases and shifts to high temperatures, respectively, with frequency. This is the typical behavior of a Maxwell-Wagner type relaxation, which is associated with the existence of significant, but inhomogeneous electrical conduction in the material. In the case of ceramics, this is thought to be related to grain boundaries having resistivity higher than that of the grain interior. Maxwell-Wagner type effects are thus found, consistently with previous reports, and set in close to RT for the ceramic samples here studied. Below this threshold, dispersion is negligible within the frequency range investigated, and a permittivity value of only 40 is obtained at $77 \mathrm{~K}$, which increases up to 48 at RT. These figures can be compared with crystal (free of domain wall contributions) values obtained by infrared reflectivity and time domain $\mathrm{THz}$ transmission spectroscopy for ceramics. ${ }^{32}$ A low temperature
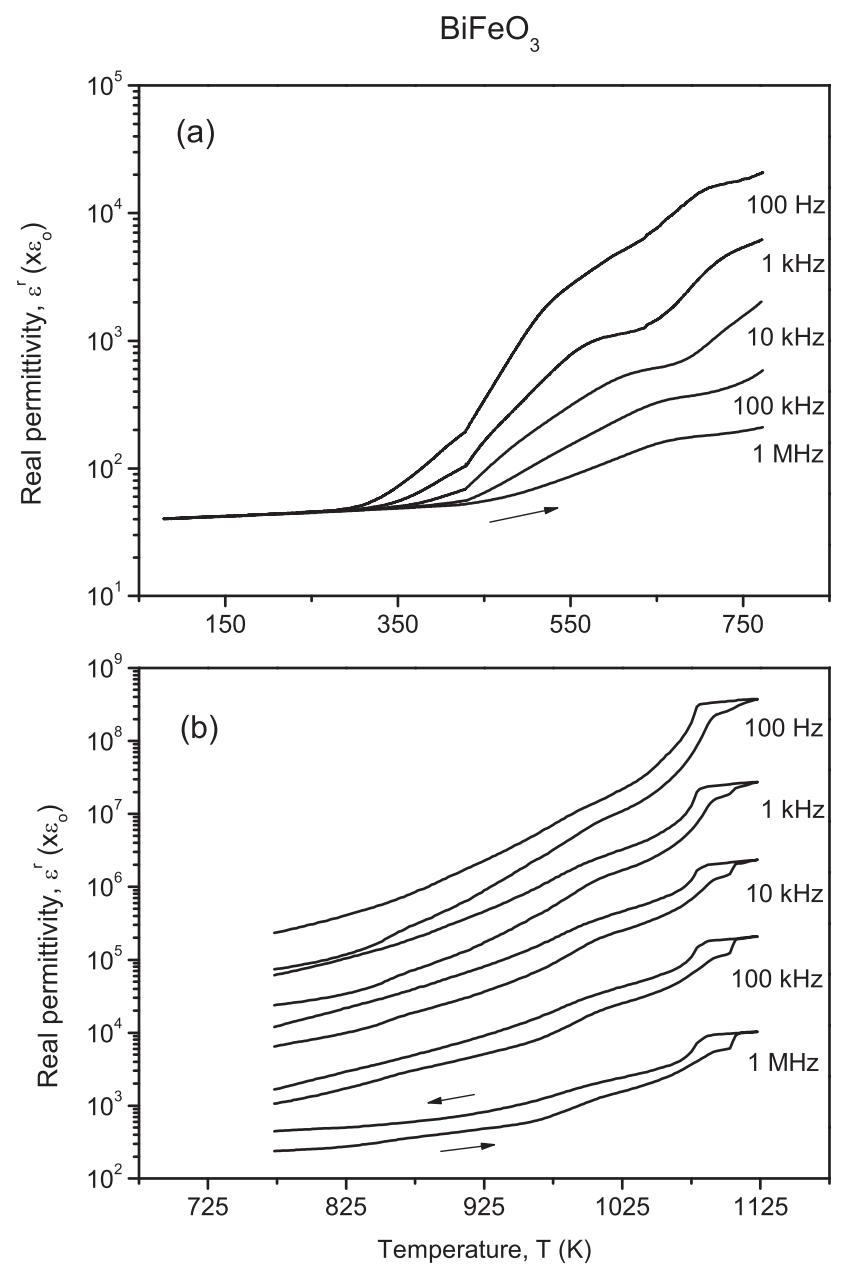

FIG. 2. Temperature dependence of the real dielectric permittivity of a $\mathrm{BiFeO}_{3}$ ceramic at several frequencies, as measured (a) during heating from 77 to $773 \mathrm{~K}$, and (b) during a thermal cycle between RT and $1123 \mathrm{~K}$. 
static permittivity of 25 was reported that increased up to 30 at room temperature. The difference might be associated with domain wall contributions, but also to the specific defect configuration. It is worth noting that Maxwell-Wagner type relaxations in the samples of Ref. 32 are already dominating the dielectric response at only $200 \mathrm{~K}$.

The real permittivity at high temperatures is separately shown in Fig. 2(b). Results during a heating/cooling cycle are presented in this case to illustrate the thermal hysteresis. Note the exponential increase with temperature, and the large frequency dispersion. This clearly indicates the response to be dominated by electrical conduction in this temperature range. Mechanism is thought to be electron hopping between $\mathrm{Fe}^{3+}$ and $\mathrm{Fe}^{2+}\left(\mathrm{Fe}_{\mathrm{Fe}}{ }^{\mathrm{x}}\right.$ and $\mathrm{Fe}_{\mathrm{Fe}}{ }^{\prime}$ in Kröger-Vink notation) cations with typical activation energies of a few tenths of $\mathrm{eV}$. Reduction results from the formation of oxygen vacancies during material preparation that also directly contribute to conductivity at high enough temperature. ${ }^{33}$ In relation to the thermal hysteresis, this points to the degradation of the sample resistivity during heating to high temperature, most probably associated with the triggering of the perovskite decomposition, as confirmed by the appearance of secondary phases after heating at $1123 \mathrm{~K}$ for $15 \mathrm{~min}$.

Perovskite decomposition, yet an issue, does not prevent the determination of the ferroelectric transition temperature from the electrical measurements, as illustrated in Fig. 3(a), where the temperature dependence above $773 \mathrm{~K}$ of the real permittivity at $1 \mathrm{MHz}$ is expanded. Note the presence of two successive anomalies at 1086 and $1105 \mathrm{~K}$ on heating that is also observed on cooling, but at lower temperatures of 1084 and $1077 \mathrm{~K}$, clearer in the derivatives further expanded in the inset. This seems to indicate the ferroelectric transition to be preceded by a previous polymorphic transition. Indeed, differential thermal analysis measurements have previously shown the existence of an intermediate phase between the ferroelectric rhombohedral phase and the high temperature paraelectric orthorhombic one, ${ }^{3,34}$ an evolution that is here confirmed with electrical measurements. This is also, as far as we know, the first observation of the dielectric anomaly associated with the ferroelectric transition for $\mathrm{BiFeO}_{3}$, which was only possible after processing materials with tailored conductivity and microstructure. All previous works reported results for solid solutions, and extrapolated them to obtain the transition temperature of the perovskite bismuth iron oxide. ${ }^{35}$

Ceramic samples also allowed high field characterization. Room temperature, low frequency ferroelectric hysteresis loops are shown in Fig. 3(b). As sintered ceramic samples showed hardly ferroelectric switching with electric fields up to $15 \mathrm{kV} \mathrm{mm}^{-1}$. Strong domain-wall clamping that hinders polarization reversal has been previously described for $\mathrm{BiFeO}_{3}$ ceramics, and proposed to be associated with the presence of oxygen vacancies and dipolar defects like $\mathrm{Fe}_{\mathrm{Fe}}{ }^{\prime}-\mathrm{V}_{\mathrm{O}} \ddot{ }$ complexes. ${ }^{36}$ Also, quenching from temperatures above the transition ones was demonstrated as an effective means of releasing the walls, and enabling switching. This procedure was also successfully used here, and results after quenching at increasing temperatures are shown in the figure. A maximum remnant polarization $P_{r}$ of $12 \mu \mathrm{Ccm}^{-2}$, and an apparent coecive field $E_{c}$ of $7.2 \mathrm{kV} \mathrm{mm}^{-1}$ were obtained with $15 \mathrm{kV} \mathrm{mm}^{-1}$ after loop compensation. This has to be compared with a remnant polarization of $19 \mu \mathrm{C} \mathrm{cm}^{-2}$ and a coercive field of $6.3 \mathrm{kV}$ $\mathrm{mm}^{-1}$ reported for the samples of Ref. 36. Differences are most probably associated with different actual defect concentrations in the materials that can be related either to the specific preparation or quenching conditions. Note anyway that ferroelectric hysteresis loops are far from saturation in both cases, for [010] crystals have a $P_{r}$ of $60 \mu \mathrm{C} \mathrm{cm}^{-2}$.

\section{B. $\mathrm{xBiFeO}_{3}-(1-\mathrm{x}) \mathrm{PbTiO}_{3}$ ceramics with $1>\mathrm{x} \geq 0.675$}

Conductivity was significantly decreased by the addition of $\mathrm{PbTiO}_{3}$, as indicated by the shift of the Maxwell-Wagner relaxation to higher temperatures, as well as by the appearance of well defined dielectric anomalies at the temperatures of the ferroelectric transitions. This is illustrated with the real permittivity of $x \mathrm{BiFeO}_{3}-(1-\mathrm{x}) \mathrm{PbTiO}_{3}$ with $\mathrm{x}=0.9$ and 0.675 in Fig. 4, where measurements during the complete thermal cycle are given. The inset shows the imaginary permittivity, directly proportional to conductivity for four compositions that reflects this diminution with $\mathrm{x}$.

The temperature dependences of the real permittivity for the same four compositions are compared in Fig. 5, as measured at $1 \mathrm{MHz}$ along the thermal cycle. Dielectric anomalies
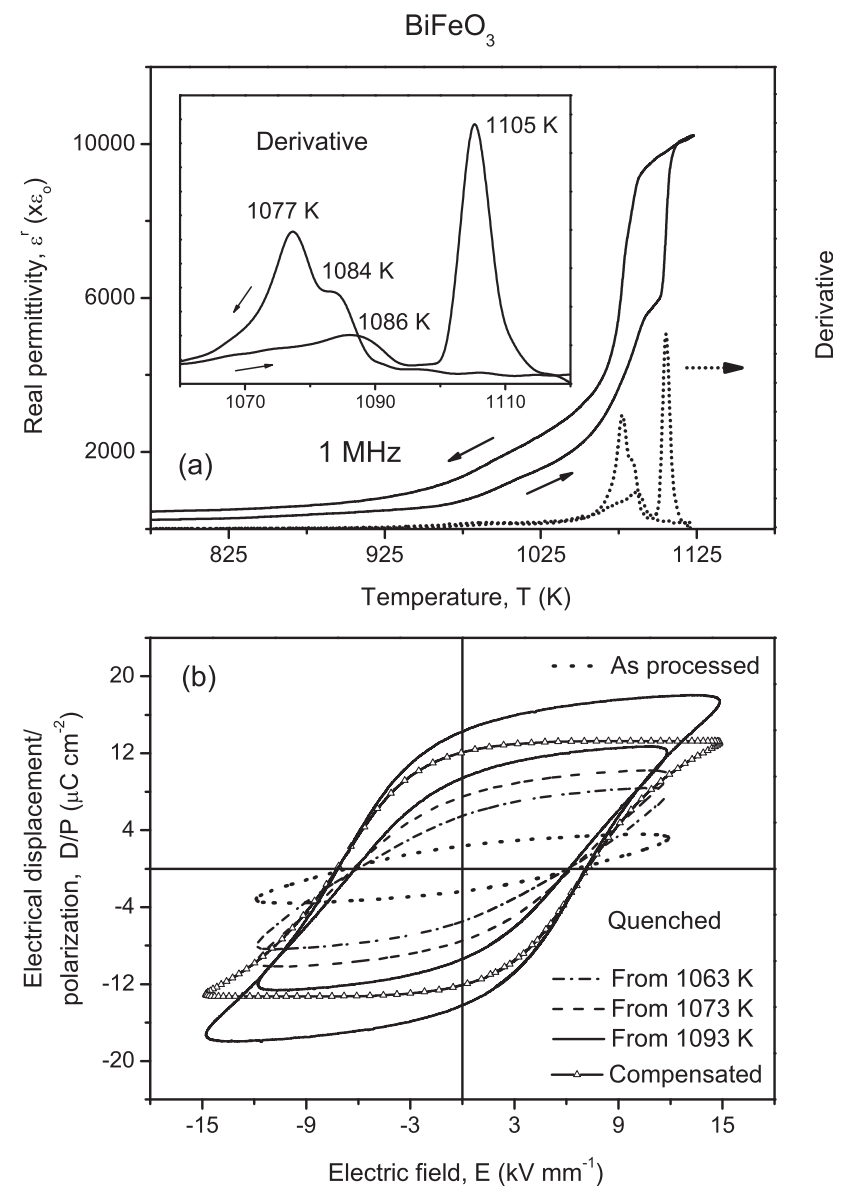

FIG. 3. Electrical properties for $\mathrm{BiFeO}_{3}$ ceramics: (a) temperature dependence of the real permittivity at $1 \mathrm{MHz}$, as measured during a thermal cycle across the ferroelectric transition (the derivative is also given and further expanded in the inset), and (b) ferroelectric hysteresis loops before and after quenching from increasing temperatures (non-compensated loops are given but for the one recorded at the maximum field of $15 \mathrm{kV} \mathrm{mm}^{-1}$ ). 

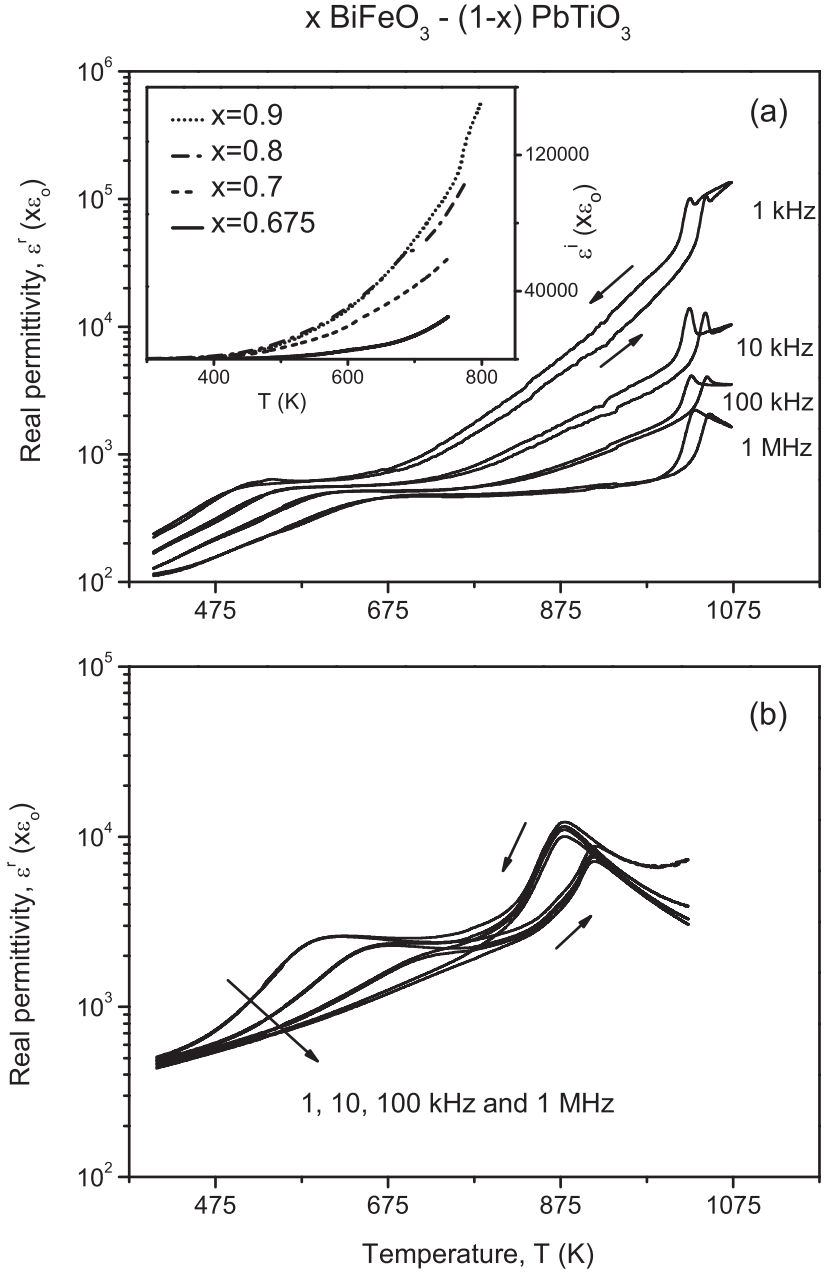

FIG. 4. Temperature dependence of the real permittivity of $\mathrm{x} \mathrm{BiFeO}_{3}-(1-\mathrm{x})$ $\mathrm{PbTiO}_{3}$ ceramics with (a) $\mathrm{x}=0.9$, and (b) 0.675 at several frequencies, as measured during a thermal cycle between RT and $1073 \mathrm{~K}$. The inset shows the imaginary permittivity for $\mathrm{x} \mathrm{BiFeO}_{3}-(1-\mathrm{x}) \mathrm{PbTiO}_{3}$ ceramics with $0.9 \geq x \geq 0.675$ at $1 \mathrm{MHz}$.

typical of first order ferroelectric transitions are found at temperatures that decrease with $\mathrm{x}$. The transition thermal hysteresis also diminish from $\mathrm{x}=1$ to 0.7 , yet an anomalous large value is found for $\mathrm{x}=0.675$. Note that the transition for this $x$ value takes place on heating at a temperature higher than that for $\mathrm{x}=0.7$. This is the composition at the core of the MPB, in which a significant fraction of tetragonal phase coexists with the monoclinic one at room temperature. Large differences in transition strain exist between the two polymorphs. ${ }^{19}$ Enhanced hysteresis, thus, is most probably a consequence of the different sequences of polymorphic transitions on heating and cooling, affected by the evolving ceramic stresses, likely from the tetragonal phase on heating and to the monoclinic one on cooling for $x=0.675$. This is further complicated by the presence of a high temperature intermediate isostructural phase with reduced cell distortion between the ferroelectric and paraelectric phases at the tetragonal side of the phase diagram, which has associated large negative volume expansion. ${ }^{37}$

A second remarkable issue is the small dielectric anomaly for $\mathrm{x}=0.9$ as compared with compositions with smaller $x$. This was consistently observed for a range of samples processed at different conditions and thus, with varying

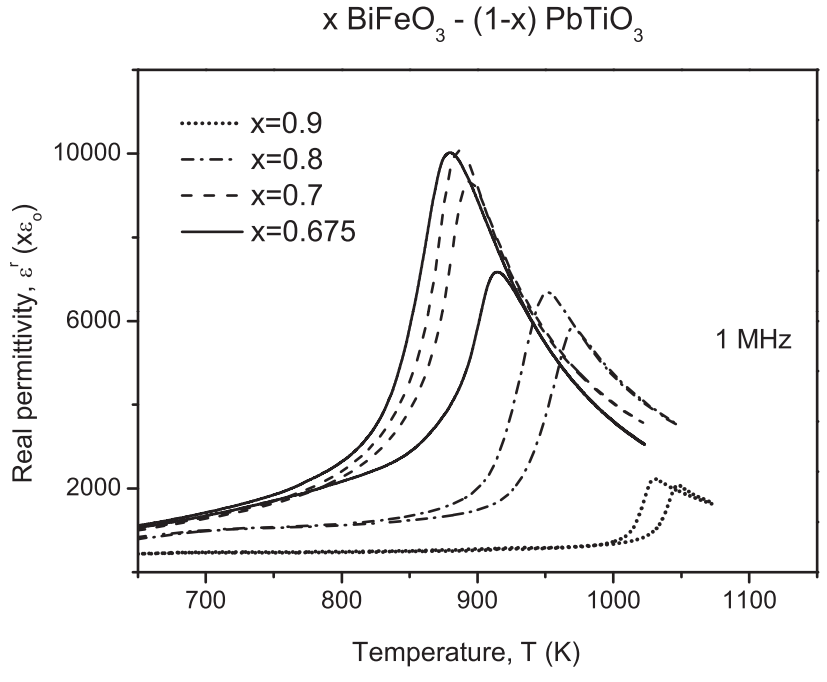

FIG. 5. Temperature dependence of the real permittivity for $x$ $\mathrm{BiFeO}_{3}-(1-\mathrm{x}) \mathrm{PbTiO}_{3}$ ceramics with $0.9 \geq \mathrm{x} \geq 0.675$ at $1 \mathrm{MHz}$, as measured during a thermal cycle between RT and $1073 \mathrm{~K}$.

conductivity and microstructure, so it is an actual feature of $0.9 \mathrm{BiFeO}_{3}-0.1 \mathrm{PbTiO}_{3}$. This composition has been shown to be at the edge of the monoclinic $C c$ existence range. ${ }^{19} \mathrm{We}$ will come back to this point in Sec. IV.
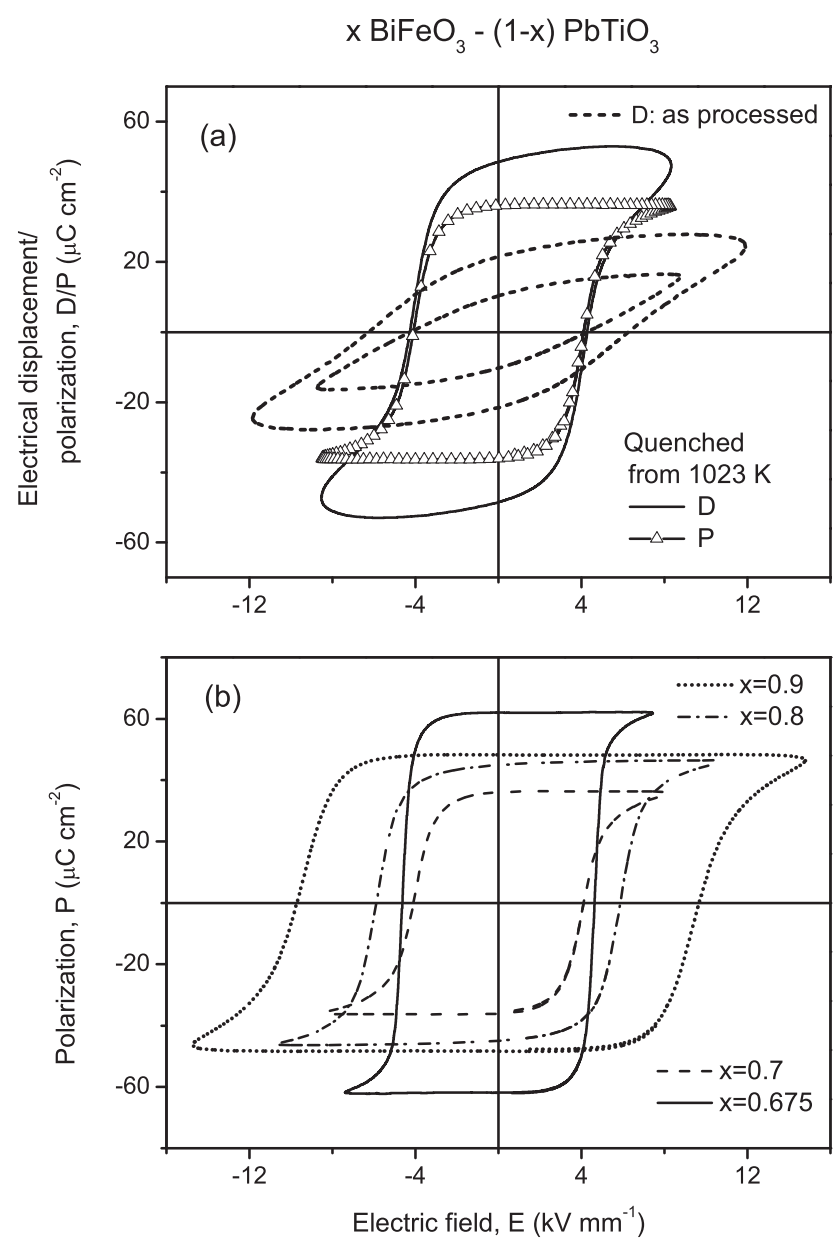

FIG. 6. Ferroelectric hysteresis loops for $\mathrm{x} \mathrm{BiFeO}_{3}-(1-\mathrm{x}) \mathrm{PbTiO}_{3}$ ceramics with (a) $x=0.7$ before and after quenching, and (b) $0.9 \geq x \geq 0.675$ after quenching. Only compensated loops are given in the latter case. 
As processed samples showed hardly ferroelectric switching up to the electrical breakdown fields, as previously reported for $0.675 \mathrm{BiFeO}_{3}-0.325 \mathrm{PbTiO}_{3} .{ }^{25}$ Like the $\mathrm{BiFeO}_{3}$ case, this was due to the domain wall clamping by defects, proposed to be $\mathrm{Fe}_{\mathrm{Fe}}{ }^{\prime}-\mathrm{V}_{\mathrm{O}} \ddot{\mathrm{O}}$ complexes, and again quenching from temperatures above the ferroelectric transition was an effective means of releasing the walls, as also shown in Ref. 25 and illustrated in Fig. 6(a) for a different composition $(\mathrm{x}=0.7)$. Saturation could be approached for all materials with $0.9 \geq \mathrm{x} \geq 0.675$, certainly thanks to the significant decrease of the coercive field with $\mathrm{x}$. This can be clearly seen in Fig. 6(b), where ferroelectric hysteresis loops for the four compositions are compared after compensation.

\section{C. $x \mathrm{BiFeO}_{3}-(1-\mathrm{x}) \mathrm{PbTiO}_{3}$ ceramics with $\mathrm{x}<0.675$}

The temperature dependence of the real permittivity for a x $\mathrm{BiFeO}_{3}-(1-\mathrm{x}) \mathrm{PbTiO}_{3}$ ceramic with $\mathrm{x}=0.6$ is shown in Fig. 7. Curves at several frequencies are only given on heating for clarity, though the thermal hysteresis is included as an inset for $1 \mathrm{MHz}$. Note again the presence of the Maxwell-Wagner type relaxation, and of the dielectric anomaly associated with the ferroelectric transition at $877 \mathrm{~K}$. Note also the decrease of the thermal hysteresis in the tetragonal field of the phase diagram after having reached very high values at the MPB.

Ferroelectric characterization was challenging in this compositional range. Once again, as processed samples showed no ferroelectric switching up to the electrical breakdown, but this time quenching resulted in microcracking and in significant leakage, which prevented saturation to be approached. This phenomenology is also illustrated in the figure where ferroelectric loops are given. Though an actual value could not be obtained, results strongly suggested compositions at the tetragonal side of the MPB to have a very high coercive field, even higher than that of $\mathrm{BiFeO}_{3}$.

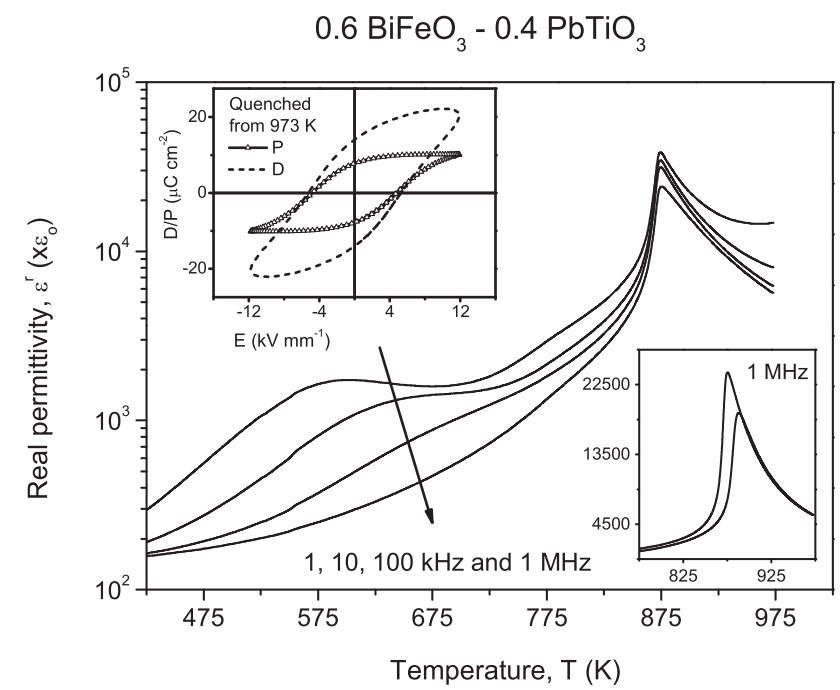

FIG. 7. Temperature dependence of the real permittivity of a 0.6 $\mathrm{BiFeO}_{3}-0.4 \mathrm{PbTiO}_{3}$ ceramic at several frequencies, as measured during heating. Thermal hysteresis at $1 \mathrm{MHz}$ is given in the inset at the bottom right corner. The second inset at the top left corner shows a ferroelectric hysteresis loop measured after quenching, before and after its compensation.

\section{DISCUSSION}

Though results have already been preliminarily discussed, a thorough discussion of the evolution of properties across the solid solution, and of its relationship with the previously reported perovskite structural evolution has not been done, and it is the objective of this section.

Results have allowed the ferroelectric transition temperatures to be determined from $\mathrm{BiFeO}_{3}$, along the perovskite $\mathrm{x}$ $\mathrm{BiFeO}_{3}-(1-\mathrm{x}) \mathrm{PbTiO}_{3}$ solid solution, and down to the tetragonal field of the phase diagram. Values are given in Fig. 8 (a). Note the continuous decrease with $\mathrm{x}$ across the rhombohedral/monoclinic phases, from $1105 \mathrm{~K}$ for $\mathrm{x}=1$ down to $894 \mathrm{~K}$ for $\mathrm{x}=0.7$ (values on heating). Note also the discontinuity at the MPB that most probably reflects the different sequences of polymorphic transitions on heating and cooling for $\mathrm{x}=0.675$, as discussed above. Back to the rhombohedral/monoclinic field, no discontinuity can be seen at the $R 3 c-C c$ boundary that must be around $\mathrm{x}=0.9$. However, it is remarkable the evolution of the dielectric anomaly, basically of its height from $\mathrm{x}=0.9$ to 0.8 ; permittivity only increases from $\sim 700$ to 2000 for $\mathrm{x}=0.9$ but raises from 830 to 6000 (and from 1600 to 9400) for $\mathrm{x}=0.8$ (and 0.7), as shown in Fig. 5. This difference might be associated with this

$$
x \mathrm{BiFeO}_{3}-(1-\mathrm{x}) \mathrm{PbTiO}_{3}
$$
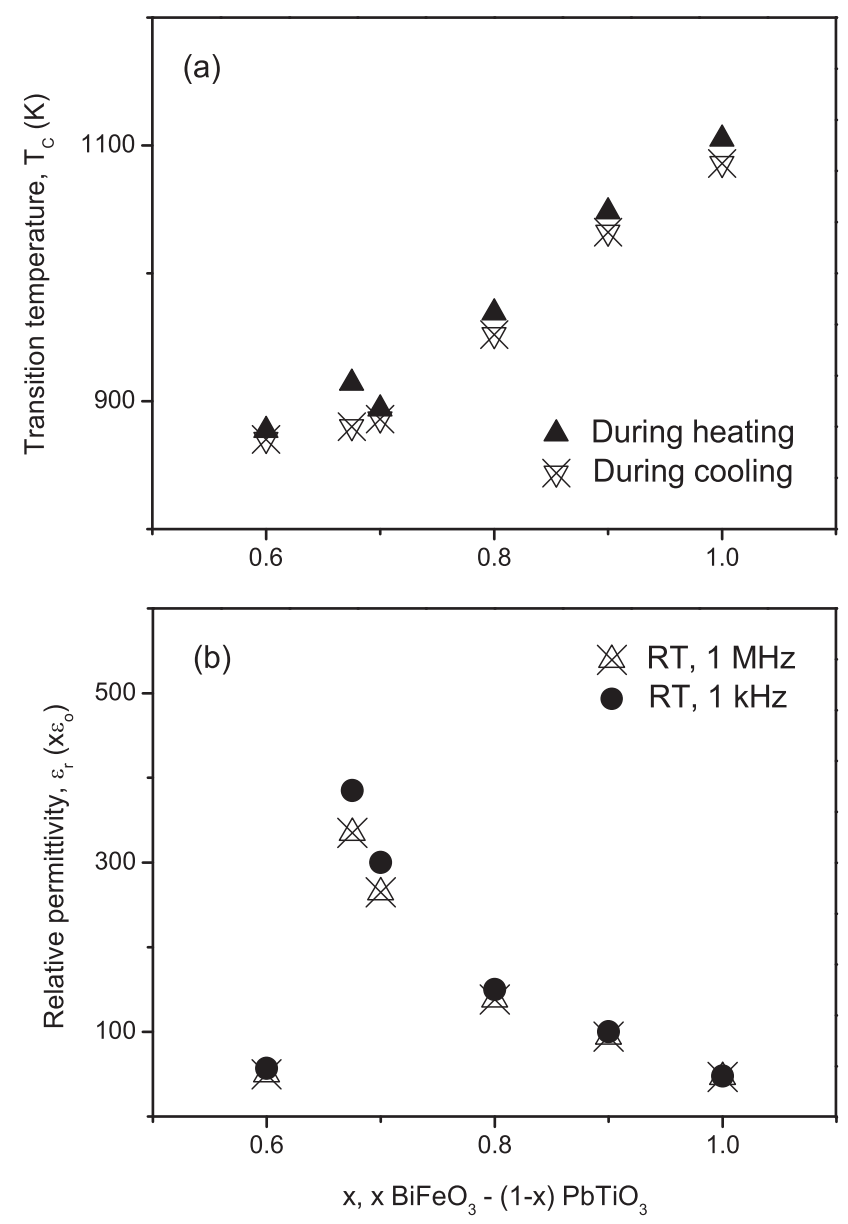

FIG. 8. (a) Transition temperatures and (b) room temperature relative dielec-

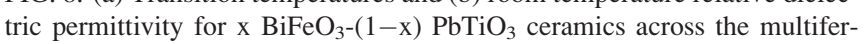
roic morphotropic phase boundary. 
boundary, so as $\mathrm{x}=0.9$ and 0.8 would be at the rhombohedral and monoclinic side, respectively. Reasons are not clear at this point, but note that the high temperature paraelectric parent phase must change across the system, for it is orthorhombic Pbnm in the case of $\mathrm{BiFeO}_{3}$, but cubic Pm3m at the MPB.

Results have also allowed the actual room temperature permittivity, free of conduction artifacts to be obtained along the perovskite solid solution. Values at two frequencies ( $1 \mathrm{kHz}$ and $1 \mathrm{MHz}$ ) are given in Fig. 8(b). Note the negligible dispersion, which demonstrate values not to be affected by the Maxwell-Wagner relaxation that is triggered at higher temperatures. Most remarkable result is the existence of a clear enhancement of polarizability at the morphotropic phase boundary, as widely observed in other perovskite binary systems. A maximum value of 335 is found for $\mathrm{x}=0.675$. This must be compared with a crystal permittivity of 350 for MPB $\mathrm{Pb}(\mathrm{Zr}, \mathrm{Ti}) \mathrm{O}_{3}$ ceramics, which is raised up to 1200 by domain wall contributions. ${ }^{38}$ Even higher figures above 5000 are found for relaxor-based systems like $\mathrm{Pb}\left(\mathrm{Mg}_{1 / 3} \mathrm{Nb}_{2 / 3}\right) \mathrm{O}_{3}-\mathrm{PbTiO}_{3}$, ${ }^{39}$ though this very-high polarizability is a consequence of the distinctive hierarchical domain configuration presented by these materials at different scales. ${ }^{40}$ Polarizability of $\mathrm{BiFeO}_{3}-\mathrm{PbTiO}_{3}$, thus, must be better compared with that of $\mathrm{Pb}(\mathrm{Zr}, \mathrm{Ti}) \mathrm{O}_{3}$, and indeed figures are quite close to those of the intrinsic permittivity. This might suggest a strongly reduced, if any contribution of domain walls. We will come back to this point later on.

The evolution of the ferroelectric parameters can be also discussed. Remnant polarization $P_{R}$ as a function of maximum electric field for materials from $\mathrm{x}=1$ down to 0.675 are shown in Fig. 9(a). Note that saturation is approached in all cases but for $x=1$. This is better seen in the derivative of the curves, displayed in Fig. 9(b) and that shows well defined maxima but for the latter case. Their position can be taken as a measurement of the coercive field $E_{C}$ that would then decrease from $12 \mathrm{kV} \mathrm{mm}^{-1}$ for $\mathrm{x}=0.9$, down to 8 and $5 \mathrm{kV}$ $\mathrm{mm}^{-1}$ for $\mathrm{x}=0.8$ and 0.7 , respectively. Saturation being reached allows some insight into the evolution of the electrical polarization to be gained. Remnant (equal to spontaneous) polarizations of 46 and $45 \mu \mathrm{C} \mathrm{cm}^{-2}$ are obtained for $\mathrm{x}=0.9$ and 0.8 , respectively, that were proposed to be at the rhombohedral and monoclinic sides of the $R 3 c-C c$ boundary. Spontaneous polarization thus does not significantly change across it. However, coercive field drops from 12 down to $8 \mathrm{kV} \mathrm{mm}{ }^{-1}$, which suggests a deep modification of the domain configuration accompanying the transition.

The electrical polarization does decrease with $\mathrm{x}$ within the monoclinic phase along with the coercive field, down to $P_{R}$ and $E_{C}$ values of $36 \mu \mathrm{C} \mathrm{cm}^{-2}$ and $5 \mathrm{kV} \mathrm{mm}^{-1}$, respectively. Beyond this $\mathrm{x}$ and entering the $\mathrm{MPB}, P_{R}$ raises up to a very large value of $63 \mu \mathrm{C} \mathrm{cm}^{-2}$ for $\mathrm{x}=0.675$, while $E_{C}$ stays at $4.5 \mathrm{kV} \mathrm{mm}^{-1}$. On one hand, $P_{R}$ was decreasing with $\mathrm{x}$ in the monoclinic phase region on approaching the MPB, so an increase of the spontaneous polarization of the monoclinic polymorphs at the MPB cannot be expected. On the other hand, though the ultrahigh crystal cell distortion of the tetragonal phases at the MPB, $\mathrm{c} / \mathrm{a} \approx 1.18$ for $\mathrm{x}=0.31,{ }^{16}$ must have associated a very large polarization, coercive field should be also very high, comparable or even higher than the one found for rhombohedral $0.9 \mathrm{BiFeO}_{3}-0.1 \mathrm{PbTiO}_{3}$ phase, $12 \mathrm{kV} \mathrm{mm}^{-1}$. Therefore, one has to accept that this extremely large remnant polarization is a MPB phenomena, most probably associated with a reversible monoclinic to tetragonal phase transition under cycling at high field. Indeed, a very high phase-change electromechanical response has been recently reported for $0.675 \mathrm{BiFeO}_{3}-0.325 \mathrm{PbTiO}_{3}{ }^{25} \mathrm{~A}$ threshold field of $1.1 \mathrm{kV} \mathrm{mm}^{-1}$ was reported at $420 \mathrm{~K}$ that decreased with temperature, which is consistent with a value of $\sim 4.5 \mathrm{kV} \mathrm{mm}^{-1}$ at room temperature.

Note that this polarization figure is for a ceramic, so the spontaneous polarization must be significantly higher. Its calculation from the remnant polarization requires knowledge of the actual switching mechanism, usually of whether nucleation and growth of non- $180^{\circ}$ ferroelectric domains contribute to the process, though the occurrence of phase-change phenomena in this case complicates the problem. As a reference, and by simple geometry arguments, the spontaneous polarization is two times the saturation polarization if only $180^{\circ}$ domain reversal contributes to ferroelectric switching. This would mean a polarization of $\sim 120 \mu \mathrm{C} \mathrm{cm}^{-2}$, even larger than that of $\mathrm{BiFeO}_{3}{ }^{5} \mathrm{MPB} \mathrm{BiFeO}_{3}-\mathrm{PbTiO}_{3}$ is thus a very

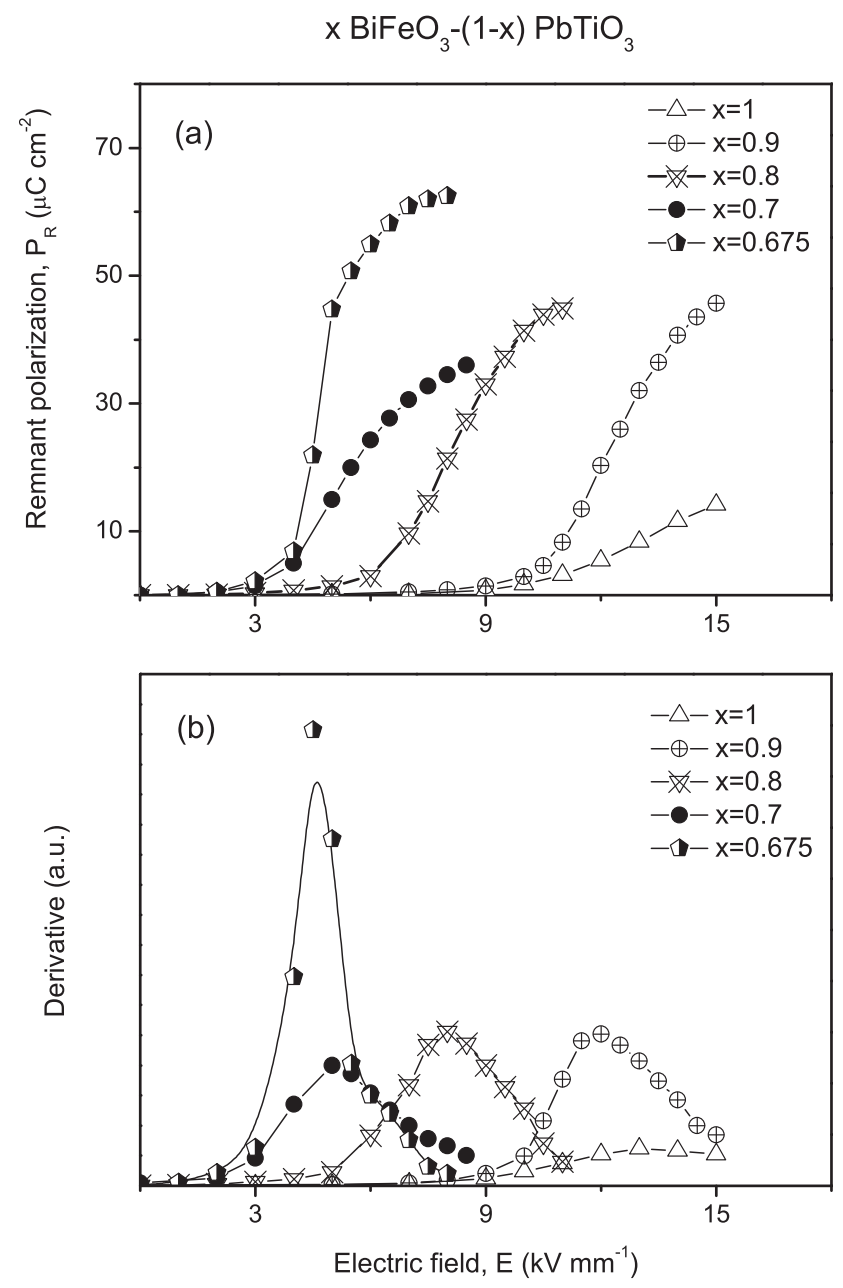

FIG. 9. (a) Remnant polarization as a function of maximum driving field for $\mathrm{x} \mathrm{BiFeO}_{3}-(1-\mathrm{x}) \mathrm{PbTiO}_{3}$ ceramics across the multiferroic morphotropic phase boundary, as determined from compensated ferroelectric hysteresis loops, (b) derivatives of (a). 
high spontaneous polarization material comparable to $\mathrm{BiFeO}_{3}$, but with a significantly smaller coercive field. This makes this material extremely interesting for non-volatile ferroelectric random access memories.

The comparatively low $E_{c}$ also facilitated poling in ceramic form, ${ }^{25}$ and allowed piezoelectric coefficients to be obtained along the perovskite solid solution. The LandauDevonshire phenomenological theory shows the piezoelectric coefficient to be proportional to the dielectric permittivity (times the polarization), and indeed an increase towards the MPB was found. Values for all compositions are provided in Table I, along with permittivity and polarization ones. A maximum $d_{33}$ of $87 \mathrm{pC} \mathrm{N}^{-1}$ was obtained for $\mathrm{x}=0.675$ that must be again compared with that of $\mathrm{Pb}(\mathrm{Zr} ; \mathrm{Ti}) \mathrm{O}_{3}$ at the MPB. A crystal piezoelectric coefficient of $80 \mathrm{pC} \mathrm{N}^{-1}$ has been reported that is raised up to $245 \mathrm{pC} \mathrm{N}^{-1}$ by non $-180^{\circ}$ domain wall contributions. ${ }^{38}$ Once again, and like the permittivity and ferroelectric hysteresis loops results, this indicates a strongly hindered domain wall mobility, and specifically the very low, if any, wall contribution, either 180 or non- $180^{\circ}$, to the material linear coefficients as a distinctive feature of the $\mathrm{BiFeO}_{3}-\mathrm{PbTiO}_{3}$ system.

Even more relevant, results also show that the lattice transverse softening, ${ }^{41}$ responsible of the high piezoelectric response of $\mathrm{MPB} \mathrm{Pb}(\mathrm{Zr}, \mathrm{Ti}) \mathrm{O}_{3}, \mathrm{~Pb}\left(\mathrm{Mg}_{1 / 3} \mathrm{Nb}_{2 / 3}\right) \mathrm{O}_{3}-\mathrm{PbTiO}_{3}$ and $\mathrm{Pb}\left(\mathrm{Zn}_{1 / 3} \mathrm{Nb}_{2 / 3}\right) \mathrm{O}_{3}-\mathrm{PbTiO}_{3}$, also takes place at the Cc- $P 4 m m$ boundary of $\mathrm{BiFeO}_{3}-\mathrm{PbTiO}_{3}$. Note that MPB $\mathrm{BiFeO}_{3}-\mathrm{PbTiO}_{3}$ presents a $d_{33}$ coefficient of $87 \mathrm{pC} \mathrm{N}^{-1}$ free of domain wall contributions, and so a field induced strain with hardly hysteresis, ${ }^{25}$ and a $T_{C}$ above $873 \mathrm{~K}$. This electromechanical response is significantly better than that of Aurivillius phases currently used for electromechanical transduction above $673 \mathrm{~K}^{42}$

Linked to the lattice transverse instability, phase-change phenomena under high field have also been described. This takes place in a magnetic system, as previously reported and confirmed by our own results. The magnetization behaviour of $0.675 \mathrm{BiFeO}_{3}-0.325 \mathrm{PbTiO}_{3}$ is given in Fig. 10. Note the presence of two successive magnetic anomalies at 200 and $380 \mathrm{~K}$, above which the system still shows a significant magnetization (Fig. 10(a)). This indicates an ordering temperature above our measuring range. Neel temperatures well above $400 \mathrm{~K}$ have been reported for monoclinic phases next to the MPB. ${ }^{15,23}$ Therefore, the observed maximum at $380 \mathrm{~K}$ must be the spin reorientation transition previously described for monoclinic $\mathrm{x} \mathrm{BiFeO}_{3}-(1-\mathrm{x}) \mathrm{PbTiO}_{3}$ with $\mathrm{x}=0.75$ and 0.73 , and that took place at $\sim 370$ and $367 \mathrm{~K}$, respectively, in these cases. ${ }^{23}$ It is remarkable the divergence of the ZFC and FC magnetizations below the reorientation transition that indicates the appearance of a small ferromagnetic component; most probably due to a magnetoelectric-coupling-induced spin canting like that described for $\mathrm{BiFeO}_{3}$. Indeed the room temperature magnetization loops show a tiny remnant magnetization of $\sim 0.01 \mathrm{emu} \mathrm{g}^{-1}$ (Fig. 10(b)). This is smaller than that reported for $\mathrm{Bi}_{0.7} \mathrm{Ba}_{0.3} \mathrm{FeO}_{3}$, but measurable. The Neel temperature of the tetragonal polymorphs has been reported to be placed below room temperature. ${ }^{15,22}$ Indeed, an anomaly is found at $200 \mathrm{~K}$ that is likely associated with this phase; recall that phase coexistence existed for this
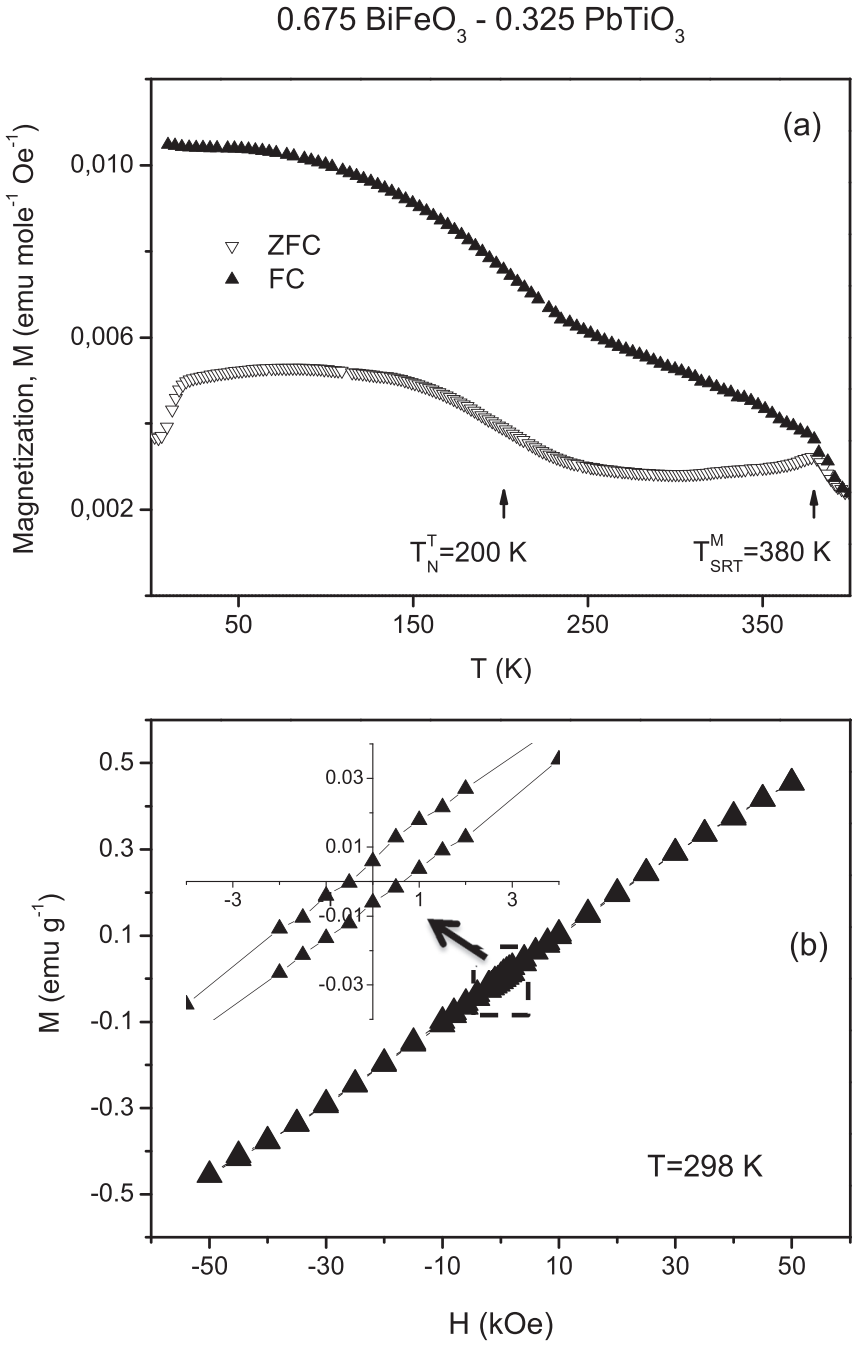

FIG. 10. Magnetic behavior of $\mathrm{BiFeO}_{3}-\mathrm{PbTiO}_{3}$ ceramics at the core of the MPB: (a) temperature dependence of magnetization (under a 500 Oe field) and (b) room temperature magnetic loop.

specific composition (see Fig. 1). Back to phase-change phenomena, the switching of a tiny but distinctive magnetization off and on can be anticipated during the reversible monoclinic to tetragonal transition under the electric field.

\section{SUMMARY AND CONCLUSIONS}

High quality ceramic materials, suitable for electrical characterization, have been processed along the perovskite $\mathrm{BiFeO}_{3}-\mathrm{PbTiO}_{3}$ solid solution, across its multiferroic morphotropic phase boundary and until to the tetragonal field of the phase diagram. A series of materials with tailored conductivity and microstructure was obtained, which enabled the electrical and electromechanical properties; all the temperature dependence of permittivity, ferroelectric hysteresis loops, and piezoelectric coefficients to be obtained across the system, along with their discussion in relation to the previously reported perovskite structural evolution. High remnant polarizations, but also very high coercive fields are found for all rhombohedral and monoclinic phases, which indicate the hindrance to domain wall movement. This is also indicated by 
the negligible wall contributions to the material linear coefficients, both to the dielectric permittivity and the piezoelectric coefficient. Nevertheless, a significant enhancement of these material linear coefficients is found at the morphotropic phase boundary, up to $\varepsilon_{33}$ and $d_{33}$ figures of $335 \varepsilon_{\mathrm{o}}$ and $87 \mathrm{pC} \mathrm{N}^{-1}$ that are comparable to the crystal ones of $\mathrm{Pb}(\mathrm{Zr}, \mathrm{Ti}) \mathrm{O}_{3}$ ceramics. This strongly suggests lattice transverse softening, responsible of the enhanced piezoelectric response of $\mathrm{Pb}(\mathrm{Zr}, \mathrm{Ti}) \mathrm{O}_{3}$ to also take place in the multiferroic system. Moreover, high field phase-change phenomena are also observed in this region, which results in a remnant polarization as high as $63 \mu \mathrm{Ccm}^{-2}$ and a comparatively low coercive field of $4.5 \mathrm{kV} \mathrm{mm}^{-1}$. Strong magnetoelectric responses can be anticipated, associated with the monoclinic to tetragonal phase transition under the electric field.

\section{ACKNOWLEDGMENTS}

Funded by MINECO (Spain) through the MAT201123709 project. Dr. H. Amorín thanks financial support by MICINN Ramón y Cajal Programme (RYC-2008-03247). Ms. C. Correas and Ms. C. M. Fernández-Posada also thank the specific financial support of FPI Programme (BES-2008005409 and BES-2012-053017, respectively). Technical support by Ms. I. Martínez (ICMM) is acknowledged. Collaboration between ICMM and Sciences Chimiques de Rennes was framed within the ESF COST Action MP0904 SIMUFER.

${ }^{1}$ J. Wang, J. B. Neaton, H. Zheng, V. Nagarajan, S. B. Ogale, B. Liu, D. Viehland, V. Vaithyanathan, D. G. Schlom, U. V. Waghmare, N. A. Spaldin, K. M. Rabe, M. Wuttig, and R. Ramesh, Science 299, 1719 (2003).

${ }^{2}$ G. Catalan and J. F. Scott, Adv. Mater. 21, 2463 (2009).

${ }^{3}$ W. Kaczmarek, Z. Pajak, and M. Polomska, Solid State Commun. 17, 807 (1975).

${ }^{4}$ F. Kubel and H. Schmid, Acta Crystallogr. Sect. B 46, 698 (1990).

${ }^{5}$ D. Lebeugle, D. Colson, A. Forrget, and M. Viret, Appl. Phys. Lett. 91, 022907 (2007).

${ }^{6}$ J. F. Scott, Science 315, 954 (2007).

${ }^{7}$ H. Ishiwara, J. Nanosci. Nanotechnol. 12, 7619 (2012).

${ }^{8}$ J. M. Moreau, C. Michel, R. Gerson, and W. J. James, J. Phys. Chem. Solids 32, 1315 (1971).

${ }^{9}$ C. Ederer and N. A. Spaldin, Phys. Rev. B 71, 060401(R) (2005).

${ }^{10}$ D. Lebeugle, D. Colson, A. Forget, M. Viret, A. M. Bataille, and A. Gukasov, Phys. Rev. Lett. 100, 227602 (2008).

${ }^{11}$ F. Bai, J. Wang, M. Wuttig, J. Li, N. Wang, A. P. Pyatakov, A. K. Zvezdin, L. E. Cross, and D. Viehland, Appl. Phys. Lett. 86, 032511 (2005).
${ }^{12}$ T. J. Park, G. C. Papaefthymiou, A. J. Viescas, A. R. Moodenbaugh, and S. S. Wong, Nano Lett. 7, 766 (2007).

${ }^{13}$ V. A. Khomchenko, D. A. Kiselev, J. M. Vieira, L. Jian, A. L. Kholkin, A. M. L. Lopes, Y. G. Pogorelov, J. P. Araujo, and M. Maglione, J. Appl. Phys. 103, 024105 (2008).

${ }^{14}$ R. T. Smith, G. D. Achenbach, R. Gerson, and W. J. James, J. Appl. Phys. 39, 70 (1968).

${ }^{15}$ W. M. Zhu, H. Y. Guo, and Z. G. Ye, Phys. Rev. B 78, 014401 (2008).

${ }^{16}$ S. Bhattacharje, S. Tripathi, and D. Pandey, Appl. Phys. Lett. 91, 042903 (2007).

${ }^{17}$ B. Noheda and D. E. Cox, Phase Transitions 79, 5 (2006)

${ }^{18}$ D. I. Woodward, I. M. Reaney, R. E. Eitel, and C. A. Randall, J. Appl. Phys. 94, 3313 (2003).

${ }^{19}$ S. Bhattacharje and D. Pandey, J. Appl. Phys. 107, 124112 (2010).

${ }^{20}$ T. P. Comyn, T. Stevenson, M. A. Al-Jawad, S. L. Turner, R. Smith, A. J. Bell, and R. Cywinsky, J. Appl. Phys. 105, 094108 (2009).

${ }^{21}$ S. Bhattacharje, A. Senyshyn, P. S. R. Krishna, H. Fuess, and D. Pandey, Appl. Phys. Lett. 97, 262506 (2010).

${ }^{22}$ T. Comyn, T. Stevenson, M. Al-Jawad, S. L. Turner, R. I. Smith, W. G. Marshall, A. J. Bell, and R. Cywinski, Appl. Phys. Lett. 93, 232901 (2008).

${ }^{23}$ S. Bhattacharje, A. Senyshyn, H. Fuess, and D. Pandey, Phys. Rev. B 87, 054417 (2013).

${ }^{24}$ O. Dieguez and J. Iñiquez, Phys. Rev. Lett. 107, 057601 (2011).

${ }^{25}$ H. Amorín, C. Correas, P. Ramos, T. Hungría, A. Castro, and M. Algueró, Appl. Phys. Lett. 101, 172908 (2012).

${ }^{26}$ W. M. Zhu and Z. G. Ye, Appl. Phys. Lett. 89, 232904 (2006).

${ }^{27}$ T. P. Comyn, S. P. McBride, and A. J. Bell, Mater. Lett. 58, 3844 (2004).

${ }^{28}$ M. A. Khan, T. P. Comyn, and A. J. Bell, Appl. Phys. Lett. 91, 032901 (2007).

${ }^{29}$ C. Correas, T. Hungría, and A. Castro, J. Mater. Chem. 21, 3125 (2011).

${ }^{30}$ A. Moure, T. Hungria, A. Castro, J. Galy, O. Peña, J. Tartaj, and C. Moure, Chem. Mater. 22, 2908 (2010).

${ }^{31}$ A. Castro, C. Correas, O. Peña, A. R. Landa-Cánovas, M. Algueró, H. Amorín, M. Dollé, E. Vila, and T. Hungría, J. Mater. Chem. 22, 9928 (2012).

${ }^{32}$ S. Kamba, D. Nuzhnyy, N. Savinov, J. Sebek, J. Petzelt, J. Prokleska, R. Haumont, and J. Kreisel, Phys. Rev. B 75, 024403 (2007).

${ }^{33}$ R. Schmidt, W. Erenstein, T. Winiecki, F. D. Morrison, and P. Midgley, Phys. Rev. B 75, 245111 (2007).

${ }^{34}$ R. Palai, R. S. Katiyar, H. Schmid, P. Tissot, S. J. Clark, J. Robertson, S. A. T. Redfern, G. Catalan, and J. F. Scott, Phys. Rev. B 77, 014110 (2008).

${ }^{35}$ M. Polomska, W. Kaczmarek, and Z. Pajak, Phys. Status Solidi A 23, 567 (1974).

${ }^{36}$ T. Rojac, M. Kosec, B. Budic, N. Setter, and D. Damajanovic, J. Appl. Phys. 108, 074107 (2010).

${ }^{37}$ S. Bhattacharje, K. Taji, C. Moriyoshi, Y. Kuroiwa, and D. Pandey, Phys. Rev. B 84, 104116 (2011).

${ }^{38}$ Q. M. Zhang, H. Wang, N. Kim, and L. E. Cross, J. Appl. Phys. 75, 454 (1994).

${ }^{39}$ J. Kelly, M. Leonard, C. Tantigate, and A. Safari, J. Am. Ceram. Soc. 80, 957 (1997).

${ }^{40}$ G. Xu, Z. Zhong, Y. Bing, Z. G. Ye, and G. Shirane, Nature Mater. 5, 134 (2006).

${ }^{41}$ D. Damjanovic, IEEE Trans. Ultrason. Ferroelectr. Freq. Control 56, 1574 (2009).

${ }^{42}$ D. Damjanovic, Curr. Opin. Solid State Mater. Sci. 3, 469 (1998). 